\title{
TRENDING AND FORECASTING IN CONSTRUCTION OPERATIONS
}

\author{
Osama Moselhi and Xiao hui Xiao* \\ Department of Building, Civil and Environmental Engineering, Concordia University, Montreal, Canada \\ *Corresponding author (Xiaohui.xiao@snclavalin.com)
}

\begin{abstract}
This paper presents a study conducted in collaboration with large Canadian engineering, procurement and construction management (EPCM) firm to identify areas of improvement in the current process of progress reporting and forecasting project status at different targeted future dates. The study focused mainly on trending and time/Cost control of engineering, procurement and construction (EPC) projects. It encompassed a field study of the practices of the industrial collaborator, study of related materials from the literature, and development of standalone computer applications, which serves as add-on utilities to the propriety project management software of the industrial partner. The paper presents a model for improving trending and forecasting of time and cost in construction operations. The proposed model has 3 main functions: 1) trending of estimate accuracy, 2) integrated control and forecasting, and 3) progress visualization. @Risk 5.0 for excel, Windows SharePoint Server and visual basic for application (VBA) are used to develop 3 add-on tools to implement the developments made in the above 3 functions. Numerical examples based on a set of data from a pilot training project, developed by the industrial partner, are presented to illustrate the essential features of the developed model.
\end{abstract}

Keywords: Forecasting, Cost Control, Visualized Progress Reporting

\section{INTRODUCTION}

Considerable research efforts have been made to improve the effectiveness of time and cost control of engineering, procurement and construction (EPC) projects (Alshibani, 1999; Moselhi, 1993; Ji Li, 2004; Fleming and Koppelman, 2005). However, through a study conducted in collaboration with large Canadian engineering, procurement and construction management (EPCM) firm, along with related materials from literature, areas of improvement in current process of progress reporting and forecasting final cost (FFC) have been identified. These areas include: 1) implementation of earned value method $(\mathrm{EVM})$ on forecasting cost and time in large size EPC projects in practical manner, 2) trade-off between practicality and theory, 3) proper visualized reporting on construction progress using multi-media, 4) progress measurement and consolidated progress for EPC projects.

This paper presents a methodology and a prototype model that address the above cited limitations. The developed model has 3 interesting features: 1) it improves the accuracy of trending and FFC in a practical simple way, 2) it facilitates progress measurement and consolidation for overall EPC progress reporting, and 3) it provides visualized progress reports from the cost and time control point of view. Numerical examples are presented to illustrate the essential features.

\section{TRENDING AND FORECASTING FINAL COST}

There is significant literature on the topic of forecasting final cost (FFC) or estimate at completion (EAC). Paul Teicholz (1993) has developed an approach called sliding moving average approach to provide accurate, unbiased and stable forecasting of final cost. Many EVM based methods along with integration of various adjustment factors have been proposed (Christensen et al., 1995; Hassanein A. and O. Moselhi, 2003).

A field study conducted with the industrial partner resulted in a different method of calculating forecast final cost from its project management system $(\mathrm{PM}+)$ through Equation (1)

$$
F F C_{0}=T C+O C+T R+U B
$$

Where $T C=$ Total commitment, which are current awarded 
purchase orders and contracts amounts, plus approved amendments; $O C=$ all outstanding change notices for each purchase order and contract; $T R=$ Trends, which captures and accounts for uncertainties in calculating FFC; $U B=$ Unallocated Budget that are available to cover un-awarded scope of work.

This method is practical, simple and easy to use. It incorporates all outstanding changes and trends into forecasting to provide early warning. However, three of its limitations are that: 1) there is no standardized method to calculate the trend amount, 2) it applies same weight to the above 4 components to FFC, which are actually in descending sequence of certainty, and 3) its forecasting may vary significantly from period to period by just simply capturing trends.

The method developed in this paper aims to alleviate the above cited limitations, while keeping it practical and simple. The process employed in this method is depicted in Figure 1 and uses Equation (2).

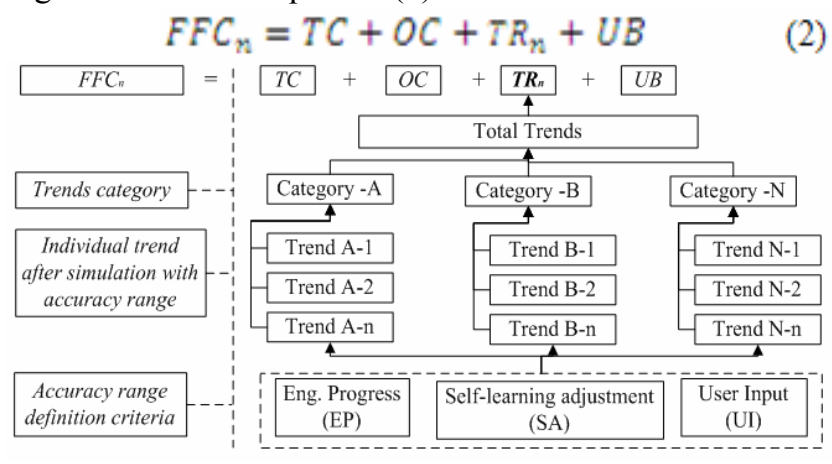

Fig. 1 Process of incorporating trend estimate accuracy into FFC calculation

The improvement is focus only on the trends. Trends are classified into different category. Trend estimate accuracy range will be provided for each trend under each category by 2 key indices: 1) engineering progress, and 2) selflearning adjustment. Trend amount with required confidence level will be registered in the FFC calculation. To keep stability, trend amount will not be updated in the system if variance is within (+/-) $10 \%$.

For an individual trend, 3 methods have been proposed to provide rational behind the estimated accuracy range. The algorithm of the first method, called engineering progress $(E P)$, is explained as follows: If $\mathrm{EP}=\mathrm{X}$, then an estimate class $\mathrm{Y}$ will be selected; based on selected $\mathrm{Y}$, accuracy range $Z$ will be produced (Figure 2). The $Z$ value will be reviewed before being used in performing the simulation process to calculate trend amount that reaches required level of confidence.

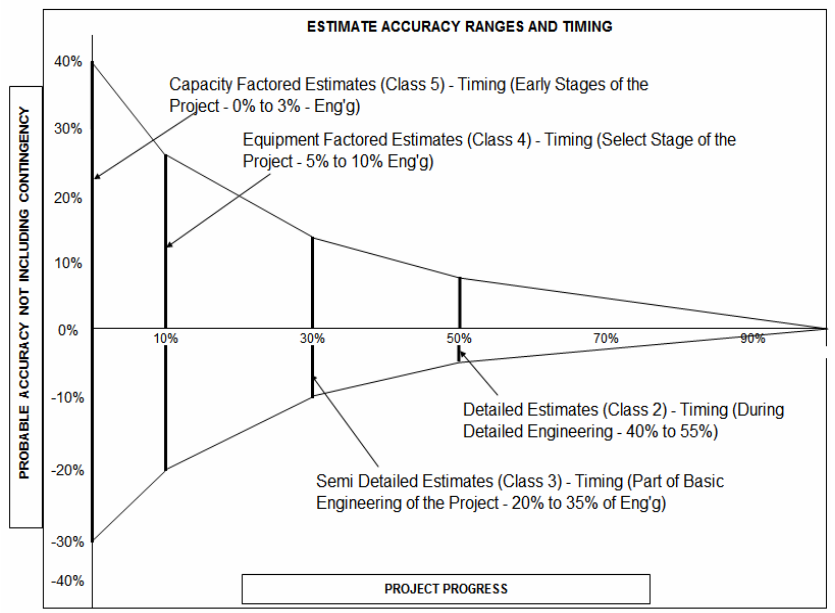

Fig. 2 Estimate accuracy range and engineering completion

The second method, called self-learning adjustment (SA), is to provide a self-learning accuracy range for specific type of trend based on its cumulative historical information. It assumes that the pattern of historical accuracy of a trend type will likely be repeated to a new trend estimate under this category.

Upper and lower bounds of accuracy will be treated separately with same algorithm. Equations (3) to (8) are used to demonstrate how the self-learning adjustment for lower bound is calculated.

$T_{\text {cub }} \%=\sum_{i=1}^{n} V W P_{i} \%$

$V W P_{i} \%=V P_{i} \% \times W P_{i} \%$

$V P_{i} \%=V_{i} / T A_{i} \times 100 \%$

$W P_{i} \%=0$, if it is black out

$T C_{\text {cub }}=\sum_{i=1}^{n} A C_{i}$

$V_{i}=A C_{i}-T A_{i}$

Where, $T_{\text {cub }} \%$ is cumulative lower bound trend accuracy range; $V W P_{i} \%$ is variance weight percentage with negative $\mathrm{V}_{\mathrm{i}} ; W P_{i} \%$ is weight percentage by trend amount with negative variance; $V P_{i} \%$ is variance percentage with negative $\mathrm{V}_{\mathrm{i}} ; \mathrm{TA}_{\mathrm{i}}$ is actual cost of a trend with negative variance $\mathrm{V}_{\mathrm{i}} ; T C_{\text {cub }}$ is total trend actual cost with negative 
variance. It has conditional sum of 2 criteria: 1) the trend is blacked out, if $\mathrm{BO}=$ "Yes", 2) the variance $\mathrm{V}_{\mathrm{i} \text {, }}$ i.e. the difference between actual cost and trend amount, if negative, then it will be used to adjust the lower bound of accuracy range.

Table 1 Numerical sample to demonstrate SA method

\begin{tabular}{|c|c|c|c|c|c|c|c|}
\hline 1 & 2 & 3 & 4 & $(5)=(4)-(3)$ & $(6)=(5) /(3)$ & 7 & 8 \\
\hline $\begin{array}{l}\text { Trend Number } \\
\text { (T) }\end{array}$ & $\begin{array}{l}\text { Weigh } \\
\text { (WP)\% }\end{array}$ & $\begin{array}{l}\text { Trend Amount } \\
\text { (TA) }\end{array}$ & $\begin{array}{l}\text { Actual Cost } \\
\text { (AC) }\end{array}$ & $\begin{array}{l}\text { Variance } \\
\text { (V) }\end{array}$ & $\begin{array}{l}\text { Variance } \\
\text { (VP)\% }\end{array}$ & $\begin{array}{c}\text { Blackout } \\
\text { (BO) }\end{array}$ & $\begin{array}{c}\text { Variance } \\
\text { Weight \% } \\
\text { (VWP) }\end{array}$ \\
\hline DDT-01 & $0 \%$ & $100 \$$ & $130 \$$ & $30 \$$ & $30 \%$ & Yes & $0.00 \%$ \\
\hline DDT-02 & $21 \%$ & $300 \$$ & $330 \$$ & $30 \$$ & $10 \%$ & No & $2.10 \%$ \\
\hline DDT-03 & $12 \%$ & $250 \$$ & $230 \$$ & $20 \$$ & $-8 \%$ & No & $-0.97 \%$ \\
\hline DDT-04 & $27 \%$ & $400 \$$ & $425 \$$ & $25 \$$ & $6 \%$ & No & $1.69 \%$ \\
\hline DDT-05 & $52 \%$ & $800 \$$ & $816 \$$ & $16 \$$ & $2 \%$ & No & $1.04 \%$ \\
\hline DDT-06 & $40 \%$ & $800 \$$ & $750 \$$ & $50 \$$ & $-6 \%$ & No & $-2.48 \%$ \\
\hline DDT-07 & $48 \%$ & $1000 \$$ & $910 \$$ & $90 \$$ & $-9 \%$ & No & $-4.33 \%$ \\
\hline
\end{tabular}

In Table 1, numerical samples are used to demonstrate the SA algorithm. Design development (DDT) is classified as one type of trend. Using the 7 cumulative trends, in that table, and their actual cost, the upper bound from cumulative trend accuracy ranges is $4.83 \%$ and that for lower bound is $-7.79 \%$. This range can be used as reference to next trend estimate.

The user input (UI) mode allows users to adjust accuracy range based on other available information, such as experiences, firm quotations and etc.

\section{PROGRESS MEASUREMENT AND CONSOLIDATION}

In general, overall progress status of EPC project comes from consolidated progress from engineering, procurement and construction with method developed in Table 2 . Different methods are available to measure progress for engineering, procurement, and construction, such as using templates, key milestones, and quantities. Many papers have been presented to automate the collection of number of labor or quantities in place. However, there is not enough to provide an overall platform to facilitate these, especially for the early stage of a project. In section we outline a mechanism to measure and to roll up progress from practical level of detail to overall EPC progress.
Table 2 Progress consolidations method in general

\begin{tabular}{lccc}
\hline Department & $\begin{array}{c}\text { Progress } \% \\
\text { (this period) } \\
(1)\end{array}$ & $\begin{array}{c}\text { Weight } \%^{*} \\
(2)\end{array}$ & $\begin{array}{c}\text { Progress after } \\
\text { Weighting } \\
(3)=(1) \times(2)\end{array}$ \\
\hline Engineering & $50 \%$ & $20 \%$ & $10.0 \%$ \\
Procurement & $10 \%$ & $30 \%$ & $3.0 \%$ \\
Construction & $5 \%$ & $45 \%$ & $2.3 \%$ \\
Management & $15 \%$ & $5 \%$ & $0.8 \%$ \\
\hline \multicolumn{2}{c}{ EPC project overall progress (this period) } & $\mathbf{1 6 . 0 \%}$ \\
\hline * Weight \% is only for reference. It comes from dollar value percentage
\end{tabular}

*Weight \% is only for reference. It comes from dollar value percentage

In the developed method EPC projects are broken down into 5 main types of work scope: 1) engineering, 2) procurement, 3) construction-direct hired labor, 4) construction-subcontract, and 5) management. For execution purposes, each type of scope is packaged, respectively in engineering work package (EWP), purchase order (PO), construction work package (CWP), subcontract, and management work package (MWP), which are considered as level 3 of detail. Accordingly, the progress tracking objects are engineering deliverables, PO pay items, field tasks, contract pay items and management tasks (level of efforts). Work breakdown structure (WBS) and commodity codes are applied to level 4 in order to provide progress report at different levels and from different perspectives. Numerous progress measurement templates have been established for different type of engineering deliverables, non-engineering deliverables, procurement services, and construction activities. See Figure 3.

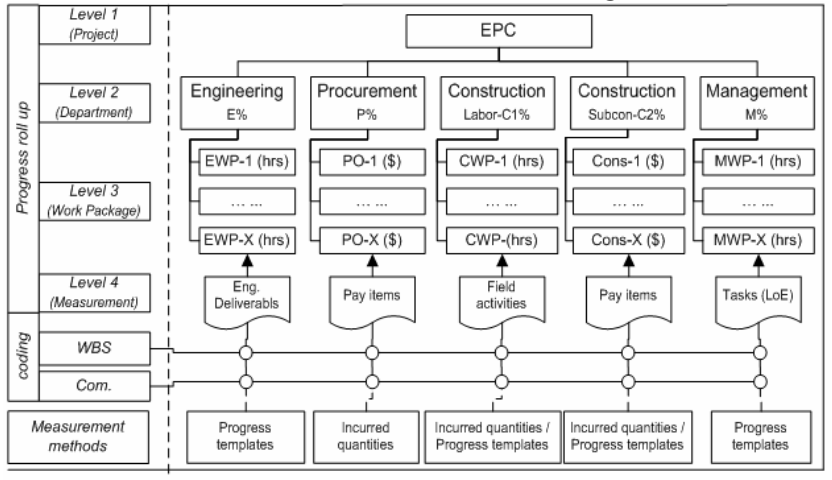

Fig. 3 Progress measurement and roll up process

This method allows progress to be consolidated from detail level to overall project level with consistency. It also provides guidance to system development. With WBS and commodity codes, it allows progress to be reported from different key perspectives, which provides information for better trending and forecasting. 


\section{VISUALIZED PROGRESS REPORTING}

Most of the project progress reports are a combination of narrative, tables with key indicators, graphic, visual photos, or 3D model. Mani G. F. (2007) proposed several semiautomated vision based approaches to further improve and facilitate the communication of progress information and decision making on corrective actions. Most of these efforts focused on visualizing either spatial building structures or sequences of construction activities. These, however, lack the flexibility and ability to visualize progress reports by plant area, work package, or commodity type, such as earthwork, concrete, and steel structure.

The approach presented in this paper aims to generate flexible visualized progress reports to provide information for better project controls, trending and forecasting. It embraces 3 key concepts: 1) each photo or video is treated as an object and is coded with those attributes, 2) each photo or video is registered in web-based database platform with mandatory attributes, 3) use report generator to provide "bar-chart" status reports from different grouping perspectives with hyperlinks to each period. They are also illustrated in Figure 4.

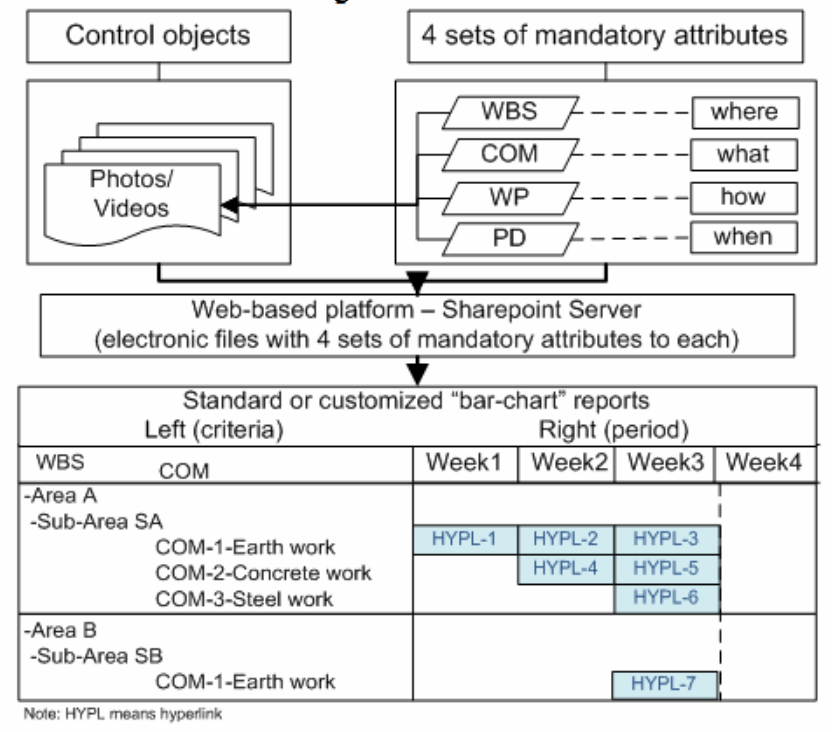

Fig. 4 Visualized progress reporting process flow

WBS, Commodity codes (COM), execution work package codes (WP), and period (PD) are chosen as 4 sets of mandatory attributes to be coded to each object. In sequence, each code is used to provide visualized and searchable information on where, what, how and when. After each object is coded, it will be uploaded to webbased platform with 4 sets of attributes as metadata, so that they can be accessed remotely. The web-based platform has the capability of dynamic filtering and grouping by metadata to support the standard "bar-chart" reports. Segment with duration of 1 week is the basic element of a "bar-chart". Hyperlink is embedded on each segment, for example, HYPL-1 provides a group of photos and video that happened in the first week, in the location of sub-areaSA, about earthwork activities.

This approach provides wide scope of visualized information for the whole project team to know the status. It is expected to be helpful in providing information for trending and forecasting with better understanding of current status, which enables better trending and forecasting.

\section{ADD-ON TOOLS DEVELOPMENT}

The proposed method was implemented in 3 add on tools to the integrated project management system to circumvent the identified limitations. These stand-alone tools are also capable of providing more accurate trending, forecasting and better consolidated and visualized progress reports to project team. Interface of information exchange between different systems is considered.

The add on tools were developed and implemented mainly making use of: 1) PM+; 2) Microsoft project; 3) @Risk 5.0 for Excel; 4) Power Builder 9.0 from Sybase; 5) SQL language; and 6) Windows SharePoint Services 3.0 (see Figure 5).

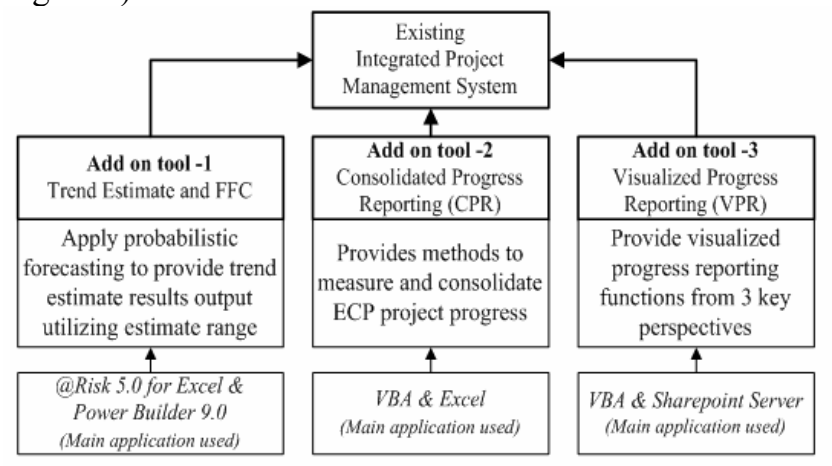

Fig.5 Functions of three add on tools

Add on tool 1 is named trend estimate (TE). It applies probabilistic forecasting to providing trend estimate results 
output utilizing estimate range and simulation. Output can be uploaded into $\mathrm{PM}+$ and integrated into forecast final cost calculation and reporting purpose.

Add on tool 2 is named consolidated progress reporting (CPR). It provides methods to measure and consolidate the progress of EPC project with capability of reporting from 2 additional perspectives, which are WBS and Commodity.

Add on tool 3 is named visualized progress reporting (VPR). It is developed based on Windows SharePoint Services 3.0. The output from this tool provides visualized progress bar-chart reports by selected criteria to provide information for better trending and forecasting preparation in construction operations.

\section{NUMBERICAL EXAMPLES AND VALIDATION}

Project data of a training project, developed in the course of the field study with the integrated project management system, was analyzed. It includes: 1) project WBS coding structure and commodity codes, 2) 10 monthly progress reports, 3) budgets, scope changes, commitments, amendments, incurred costs and trends information from 78 commitment packages, 4) a set of architecture construction drawings, and 5) a site visit. The samples of the results obtained are presented to illustrate the essential features of the 3 add-on tools.

Accuracy range and Monte Carlo simulation were applied

Table 3 Trend estimate using accuracy range from engineering completion on different selected trends based on engineering completion, self-learning adjustment, and subjective methods. The results in Table 3 demonstrate that a trend estimate reaching $90 \%$ confidence level, using subjective method, is generated. This amount is integrated into forecasting final cost calculation.

Site progress photos and videos from different periods were coded with WBS, commodity, work package, and period codes. They were loaded into the third add on tool (VPR), which was developed based on SharePoint server. One of those standard visualized progress reports grouped by WBS and commodity is shown in Figure 6 . When users move their cursors and click over the "bar chart", embedded hyperlink generated by the system will guide users to the filtered media center by period under the selected criteria.

\begin{tabular}{|c|c|c|c|c|c|c|}
\hline \multicolumn{7}{|c|}{$\begin{array}{l}\text { Visualized Progress Report } \\
\qquad B y \text { WBS / Commodity }\end{array}$} \\
\hline \multirow[t]{2}{*}{ WBS } & & $11-01-10$ & $11-01-17$ & $11-01-24$ & $11-01-31$ & $11-02-07$ \\
\hline & Commodity & Week 1 & Week 2 & Week 3 & Week 4 & Week 5 \\
\hline \multicolumn{2}{|l|}{ 2-OSBL } & & & & & \\
\hline & & & & & \\
\hline \multicolumn{2}{|c|}{\begin{tabular}{l|l}
$2-100$ & Material Handling \\
& 1 -Earthwork
\end{tabular}} & V-Info & V-Info & V-Info & V-Info & \\
\hline & 2-Concrete work & \multicolumn{3}{|c|}{ Earthwork this period - visualized } & $\underline{\text { V-Info }}$ & V-Info \\
\hline & 3-Steel Structure & & & & $\underline{\text { V-Info }}$ & V-Info \\
\hline & 4-Architecture & & & & & V-Info \\
\hline
\end{tabular}

Fig.6 Prototype visualized progress report sample

\begin{tabular}{|c|c|c|c|c|c|c|c|c|c|}
\hline \multicolumn{10}{|c|}{ Accuracy Range } \\
\hline \multicolumn{3}{|l|}{ 1-Subjective } & \multicolumn{2}{|c|}{ 3-Self-adjustment of a trend type } & end type & & & & \\
\hline \multicolumn{3}{|c|}{ 2-Engineering Completion } & \multicolumn{2}{|c|}{ 4-Self-adjustment of a trend } & \multirow{2}{*}{\multicolumn{5}{|c|}{ Subjective }} \\
\hline \multirow[b]{2}{*}{ Trend Numbe } & \multirow[b]{2}{*}{ Items } & \multirow[b]{2}{*}{ C.P } & \multirow[b]{2}{*}{ Facility } & \multirow[b]{2}{*}{ CRC } & & & & & \\
\hline & & & & & Description & \multicolumn{2}{|c|}{ Accuracy Range } & Most likely & \begin{tabular}{|c|} 
Sampled \\
(@Risk output)
\end{tabular} \\
\hline T-001 & 01 & C-3-901 & 12100 & 3110-Light Steel & LIGHT STEEL $(X<=30 \mathrm{KG} / \mathrm{M})$ & $-10.00 \%$ & $15.00 \%$ & $12000 \$$ & $12100 \$$ \\
\hline T-001 & 02 & C-3-901 & 12100 & 3120-Medium Steel & MEDIUM STEEL $(30 \mathrm{KG} / \mathrm{M}<\mathrm{X}<=80 \mathrm{KG} / \mathrm{M})$ & $-10.00 \%$ & $15.00 \%$ & $12600 \$$ & $12705 \$$ \\
\hline T-001 & 03 & C-3-901 & 12400 & 3130-Heavy structure & HEAVY STEEL $(X>80 \mathrm{KG} / \mathrm{M})$ & $-10.00 \%$ & $15.00 \%$ & $25000 \$$ & $25208 \$$ \\
\hline \multirow{2}{*}{\multicolumn{8}{|c|}{ Total }} & $55000 \$$ & $55458 \$$ \\
\hline & & & & & & & & $104600 \$$ & $105472 S$ \\
\hline \multicolumn{5}{|c|}{ Probability of meeting value of 104600} & $40.2 \%$ & 104600 & & & \\
\hline \multirow{2}{*}{\multicolumn{5}{|c|}{\begin{tabular}{|l|} 
Total budget required for $90.0 \%$ confidence \\
Extra budgets required for $90.0 \%$ confidence \\
\end{tabular}}} & $109434.56 \$$ & $90.0 \%$ & & & \\
\hline & & & & & $4834.56 \$$ & & & & \\
\hline
\end{tabular}

\section{CONCLUSIONS}

A new method to improve trending and forecasting in construction operations is presented. Its 3 key features include: 1) practical improvement on the accuracy of trending and forecasting, 2) facilitation on consistent EPC progress measurement and roll-up, and 3) visualization on progress reports from cost and time control point of view. Three add on tools are developed and implemented using @ Risk 5.0 for excel, Power Building 9.0 and Windows 
SharePoint server. Numerical examples from a pilot training project based on customized actual data are presented to demonstrate the use of the proposed method and to illustrate the features of the developed tools.

\section{REFERENCES}

[1] Alshibani, A., "A computerized cost and schedule control system for construction projects", Master's thesis, Civil, Building, and Environmental Engineering, Concordia University, Montreal, Canada, 1999.

[2] Bebawi, S., Nguyen, H., and Fauteux, J. "BLDG 7861: Business Practices in Constructions", lectures Notes, Concordia University, Montreal, Canada, 2006.

[3] Christensen, D.S, Antolini, R.C. and Mckinney, J.W., "A review of EAC Research", Journal of Cost Analysis and Management, Spring Issue, pp. 41-62, 1995.

[4] Fleming, Q. W. and Koppelman, J.M., Earned Value Project Management, $3^{\text {rd }}$ Ed., Newton Square, Pa., USA: Project Management Institute, 2005.

[5] Hassanein A., and Moselhi O., "Tracking and Control of Linear Infrastructure Projects", $5^{\text {th }}$ Construction Specialty Conference of the Canadian Society for Civil Engineering, Moncton, Nouveau-Brunswick, Canada, 2003. [6] Ji, Li. "Web-based integrated project control”, PhD's thesis, Civil, Building, and Environmental Engineering, Concordia University, Montreal, Canada, 2004.

[7] Mani, G., F. and Feniosky P., "Application of Visualization Techniques for Construction Progress Monitoring." Proceeding of the 2007 ASCE International Workshop on Computing in Civil Engineering, Pittsburgh, USA. pp. 216-223, 2007.

[8] Moselhi, O., Ji,li, and Alkass, Sabah, "Web-based integrated project control System." Construction Management and Economics. Vol. 1, pp. 35-46, 2004.

[9] Paul Teicholz, "Forecasting final cost and budget of construction projects", Journal of Computing in Civil Engineering, Vol. 7, No. 4, October, 1993.

[10] Xiao hui, Xiao, "Trending and forecasting in construction operations", Master's thesis, Civil, Building, and Environmental Engineering, Concordia University, Montreal, Canada, 2009. 